\title{
Akıllı Turizmde Büyük Veri Kullanımı: Sistematik Bir Derleme
}

\author{
DOI: 10.26466/opus.780017
}

$*$

Fatih Ercan *

* Dr. Öğr. Üyesi, Zonguldak Bülent Ecevit Üniversitesi, Kdz. Ereğli Turizm Fakültesi, Turizm İşletmeciliği, Zonguldak/Türkiye

Öz
E-Posta: fatih.ercan@beun.edu.tr
ORCID: $\quad \underline{0000-0001-6469-3000}$

Teknolojide meydana gelen gelişmeler ve kişiler arasında kullanımının yaygınlaşması sonucunda çevrimiçi ortamın günümüzde daha fazla kullanıldı̆̆ı görülmektedir. Dijital ortamda, bu mecrayı kullanan kişiler hakkında çeşitli bilgiler yer almakta ve işletmeler için bunlar günümüzde önemli bir veri kaynă̆g oluşturmaktadır. Çok büyük miktarlara ulaşan bu büyük veriler analiz edilmekte ve sunulan hizmetlerin etkinliğinin artırılmasında kullanılabilmektedir. Turizm endüstrisinde son yıllarda önem kazanan akıllı turizm uygulamalarının da müşteri istek ve beklentileri doğrultusunda geliştirildiği dikkat çekmektedir. Akıllı turizm uygulamalarında büyük veri kullanımına ilişkin çalışmalar bu doğrultuda önem kazanmaktadır. Bu bağlamda, akıllı turizm uygulamalarında büyük verinin kullanımına yönelik makalelerin içeriklerinin incelenmesi ve teorik olarak çıkarımlar elde edilmesi bu çalışmanın amacın oluşturmaktadır. Sistematik derleme yöntemi kullanılarak, belirlenen kriterlere göre uluslararası veritabanlarında makaleler taranmış ve analiz edilmiştir. Gerçekleştirilen analiz sonuçlarına göre, akıllı turizmde büyük veri kullanımı konulu az sayıda makale çalışmasının bulunduğu tespit edilmiştir. Bununla birlikte, destinasyon yönetimi, müşteri ilişkileri yönetimi, talep tahminleme ve değer oluşturma, akıllı turizmde büyük veri kullanımının en önemli fonksiyonları olarak vurgulanabilir.

Anahtar Kelimeler: Büyük Veri, Akıllı Turizm, Sistematik Derleme. 


\title{
Use of Big Data in Smart Tourism: A Systematic Review
}

\begin{abstract}
As a result of the developments in technology and its widespread use among individuals, it is seen that the online environment is used more today. In the digital environment, there are various information about the people who use this medium and these are an important data source for businesses today. This huge data, which reaches huge amounts, is analyzed and can be used to increase the efficiency of the services provided. It is noteworthy that smart tourism applications, which have gained importance in the tourism industry in recent years, have been developed in line with customer demands and expectations. Studies on the use of big data in smart tourism applications gain importance in this direction. In this context, the aim of this study is to examine the articles on the use of big data in smart tourism applications and to obtain theoretical inferences. Using the systematic review method, articles were scanned and analyzed in international databases according to the determined criteria. According to the results of the analysis carried out, it has been determined that there are few articles on the use of big data in smart tourism. However, destination management, customer relationship management, demand forecasting and value creation can be highlighted as the most important functions provided by the use of big data in smart tourism.
\end{abstract}

Keywords: Big Data, Smart Tourism, Systematic Review. 


\section{Giriş}

21. yüzyılda dünya genelinde yaşanan dijital dönüşümün, günümüzde yeni teknolojilerin gelişimiyle birlikte önemli boyutlara ulaştığı görülmektedir. İnternetin kişiler arasında kullanımının yaygınlaşmasıyla yeni teknolojiler de ortaya çıkmaya başlamıştır. Sosyal medya, akıllı mobil uygulamalar, yapay zekâ, nesnelerin interneti ve büyük veri bu yeni teknolojiler arasında öne çımaktadırlar. Akıllı mobil telefonların kullanımı ve internet erişiminin yaygınlaşması, sosyal medyayı önemli bir iletişim ve paylaşım platformu konumuna getirmektedir. Sosyal medyada yer alan kullanıcı profillerindeki bilgiler, paylaşımlar ve gönderiler kişiler hakkındaki bazı verilerin dijital ortama taşınmasına neden olmaktadır. Benzer şekilde çeşitli web siteleri de kullanıcı bilgilerinin depolandığı önemli birer veri kaynağı olabilmektedir. Artan kullanıcı sayısıyla birlikte dijital ortamdaki veriler de artmakta ve büyük boyutlara ulaşmaktadır.

Kişiler hakkında bilgi toplanmasını sağlayan teknolojilerin kullanılmastyla elde edilen büyük miktarlardaki veri (Riahi ve Riahi, 2018, s. 524) olarak büyük veri kavramını tanımlamak mümkündür. Web siteleri ve sosyal medya aracıllğıyla kullanıcılar hakkında elde edilen büyük veriler, günümüzde farklı endüstrilerde faaliyet gösteren işletmeler için olduğu gibi turizm işletmeleri için de önem taşımaktadır. Yallop ve Seraphin (2020), büyük verinin turizm endüstrisinde kişiye özel hizmet sunumlarında kullanılan en önemli araçlardan biri olduğunu belirtmektedirler. Liu, Zou, Liu ve Cheng (2019), turizm endüstrisinde çevrimiçi ortamda işletmeler ve destinasyonlar hakkında da büyük verilerin bulunduğunu ifade etmektedirler. Yazarlar, çevrimiçi ortamda bu büyük veriler içerisinden kişilerin tercihlerine uygun seyahat seçeneklerine ulaşmalarının zor olduğunu vurgulamaktadırlar. Shafiee ve Ghatari (2016), artan dijitalleşmeyle birlikte dünyadaki veri miktarının arttığını ve bu büyük verinin turizm endüstrisinde akıllı seyahat deneyimlerinin oluşturulmasında önemli fırsatlar sunduğunu belirtmektedirler. Dolayısıyla büyük veri, turizm endüstrisinde hem hizmet sağlayıcılar hem de tüketiciler için önemli bir araç konumundadır.

Turizm endüstrisinde son yıllarda büyük miktarlardaki verinin analizine yönelik araştırma ve uygulamalarda artış olduğu gözlemlenmektedir (Mariani, Baggio, Fuchs ve Höepken, 2018). Bununla birlikte, günümüzde büyük 
veri analizlerinden elde edilen bilgiler kullanılarak akıllı teknolojilerin geliştirilmesi ve çeşitli alanlarda kullanımı mümkün olabilmektedir. Bu şekilde geliştirilen akıllı teknolojiye sahip makinelerin fiziki üretimin yanı sıra karar alma ve iş süreçlerinde yenilik oluşturmak için de kullanıldığı görülmektedir (Shang ve You, 2019). Çeşitli çevrimiçi platformlardan elde edilen büyük veriler kullanılarak oluşturulan akıllı teknolojiler ile turizm endüstrisinde talep tahminleme ( $\mathrm{Li}, \mathrm{Hu}$ ve $\mathrm{Li}, 2020)$, müşteri bilgileri yönetimi (Centobelli ve Ndou, 2019), ziyaretçi davranışlarının ve tercihlerinin belirlenmesi (Iorio, Pandolfo, D'Ambrosio ve Siciliano, 2019) mümkün olabilmektedir. Büyük veri kullanılarak geliştirilen akıllı teknolojiler, turizm endüstrisinde önemli bir hizmet destek aracıdır. Ayrıca, akıllı turizmde büyük veri kullanımı, son yıllarda akademik çalışmalarda ele alınmaya başlanan güncel konular arasinda dikkat çekmektedir.

Bu çalışmanın amacı, akıllı turizmde büyük veri kullanımına ilişkin yayınlanan makalelerin kapsamını ve içeriklerini analiz ederek konu hakkında teorik bilgiler elde etmek ve çıkarımlarda bulunmaktır. İlgili literatürde büyük veri ve akıllı turizm son 10 yıldır çalışılan konular arasındadır. Büyük verinin akıllı turizm uygulamalarında kullanılması ve amaçları ise son yıllardaki yeni çalışma alanı olarak ortaya çıkmaktadır. Dolayısıyla, bu alandaki çalışmaların sistematik analizi, konunun teorik olarak detaylı bir şekilde incelenmesini sağlayacaktır. Bu çalışma sonucunda elde edilecek teorik bilgilerin bu konuda turizmle ilgili literatürün gelişimine katkı sağlaması da beklenmektedir. Ayrıca, turizm endüstrisindeki hizmet sağlayıcılar ve araştırmacllar için bu çalışmanın önemli bir yol gösterici olacağı düşünülmektedir.

\section{Kavramsal Çerçeve}

Son yillarda teknolojide meydana gelen en önemli değişim ve yeniliklerden biri olarak büyük veriyi göstermek mümkündür. Büyük veri teknolojisi; web siteleri, sosyal medya, akıllı mobil cihazlar aracilığıla toplanan büyük miktarlardaki çeşitli veri kümesini ifade etmektedir. Verilerin günümüzde teknolojinin yardımıyla hız, çeşitlilik ve hacim açısından büyük artış göstermesi büyük veri kavramını ortaya çıarmıştır (Doğan ve Arslantekin, 2016, s. 15). Bugün, dijital araçlarla yaptığımız her işlem arkamızda bir veri kaydı bırakmaktadır. Büyük veri, çok büyük boyutlara ulaşan bu verilerin anlamlı ve işlenebilir biçime dönüştürülmüş halidir. Büyük verilerin analizi, sadece sosyal 
ağların ilgi alanına girmemekte, aynı zamanda şirketlerin temel işlevlerinden biri olmaktadır (Koyuncu, 2012). Dolayısıyla, dijital ortamda sadece verinin elde edilmesi değil, aynı zamanda bu verinin işlenmesi ve anlamlı bir hale getirilmesiyle işletmeler tarafından büyük veri kullanılmaktadır.

Aktan (2018, s. 1), günümüzde akıllı cihazlar aracılığıyla üretilen verilerin büyük boyutlara ulaştığını, yapısal, yarı yapısal ve yapısal olmayan veri bütünlerinin büyük veriyi oluşturduğunu belirtmektedir. Yazar, çok sayıda endüstriyel faaliyet alanında yeni veri üreterek ya da mevcut veriyi sayısallaştırarak büyük veriye kaynak oluşturulduğuna da dikkat çekmektedir. Ayrıca, büyük veriden ekonomik değer elde edilebilmesi için işletmelerin bu verileri ileri analitik yöntemlerle işlemesi ve anlamlı bir hale getirmesi gerekliliğinin de altı çizilmektedir. Teknolojide yaşanan hızlı gelişmeler ve kullanımının yaygınlaşmasıyla artan büyük ve karmaşık verilerin işletmeler tarafından kullanılması son yıllarda önem kazanmaya başlayan konular arasındadır. Büyük verilerden işletme kararlarında kullanılabilecek bilgilerin üretilmesi ve anlamlandırılması süreci "analitik" olarak isimlendirilmektedir. Analitik yöntemlerle verilerin işlenmesi ve işletmeler için faydalı bilgilere dönüştürülmesi önemli bir zorunluluk olarak nitelendirilmektedir (Altunışık, 2015, s.46).

Günümüzde son derece popüler bir hale gelen büyük verinin, bilgi ve iletişim teknolojileri için yeni bir devrin başlangıcı olarak nitelendirildiği görülmektedir. İnternet teknolojileri; web siteleri, çeşitli sosyal medya uygulamaları, sensörler ve daha birçok dijital araç sayesinde her an veri toplar durumdadır. Bu veri yığını içerisinden gerekli veriyi seçerek toplamak, işlemek, kullanıma hazır hale getirmek ve depolamak gerekmektedir. Toplanan bu veriler, pazarlama, halkla ilişkiler, bankacılık, güvenlik gibi alanlarla birlikte çeşitli araştırmalar için de kullanılabilir niteliktedir (Doğan ve Arslantekin, 2016). Son yıllarda büyük verinin turizm endüstrisinde kullanımına yönelik çeşitli araştırmaların gerçekleştirilmeye başlandığı dikkat çekmektedir (Centobelli ve Ndou, 2019; Li ve Law, 2020; Yin ve Zhu, 2017).

Li ve Law (2020), turizmde büyük veri kullanımı ile ilgili disiplinlerarası çalışmalar yürütüldügüunü, bu çalışmalarda genel olarak gizlilik, veri kalitesi ve uygun veri kullanımı üzerine odaklanıldığını belirtmektedirler. Turizm endüstrisinde büyük veri sadece dijital pazarlamada değil, talep tahminlemede, istatistiksel çalışmalarda da önemli bir kaynak olabilmektedir (Volo, 2020). Riahi ve Riahi (2018), dijital verinin genellikle internete bağlı cihazların kullanımı sonucunda üretildiğini, akıllı telefonlar, tablet ve bilgisayarların 
kullanıcılar hakkındaki veriyi yaydıklarını ifade etmektedirler. Yazarlara göre, birbirine bağlı akıllı cihazlar tüketicilerin kullanım alışkanlıkları hakkında bilgileri işletmelere iletmekte, veriler oluşturmaktadır. Burada büyük veri kullanımı ve akıllı teknolojiler arasındaki ilişkiye yapılan vurgu dikkat çekmektedir. İlgili literatürde büyük verinin elde edilmesi ve turizmde kullanılmasında akıllı teknolojilerin rolünün üzerinde durulduğu görülmektedir.

Akıllı teknolojiler, turizm endüstrisinde Endüstri 4.0 devrimiyle birlikte kullanılmaya başlanan, Akıllı Turizm ya da Turizm 4.0 kavramlarını meydana getiren yeni nesil turizm teknolojileri olarak turizm açısından değerlendirilebilir. Akıllı turizmi, akıllı teknolojilerin turizm endüstrisindeki uygulamaları olarak açıklayan Li, Hu, Huang ve Duan (2017), bilgi teknolojileri kullanılarak turistik hizmetlerin sunulmasının akıllı turizmin odak noktasını oluşturduğunu belirtmektedirler. Femenia-Serra, Neuhofer ve Ivars-Baidal (2019), bilgi ve iletişim teknolojilerinin turizm işletmeleri, destinasyonlar ve turistler arasındaki ilişki üzerine etkisi kapsamında akıllı turizm ve akıllı destinasyonları ele almaktadırlar. Yazarlar, turizm endüstrisinde akıllı teknolojiler kullanılarak kişiye özel hizmet oluşturulmasında büyük veriye olan ihtiyaca dikkat çekmektedirler. Diğer bir ifadeyle, akıllı turizm teknolojileri turizm hizmetlerinin kişiselleştirilmesinde müşteriler hakkındaki büyük veriye ihtiyaç duymaktadır. Benzer şekilde Xu, Huang, Zhu ve Zhang (2018), akıllı destinasyonların yönetimi, hizmetlerin geliştirilmesi ve şehrin tanıtımında büyük verinin önemli bir araç olduğunu belirtmektedirler.

Literatür incelendiğinde, turizm endüstrisinde akıllı teknolojilerin kullanımı, akıllı turizm ve akıllı destinasyon kavramları üzerine çalışmaların son yıllarda yoğunlaştığı görülmektedir. Bununla birlikte, işletmelerde ve kişiler arasında teknoloji kullanımının yaygınlaşmasıyla birlikte gündeme gelen büyük verinin, turizm endüstrisi açısından incelenen konular arasında olduğu dikkat çekmektedir. Akıllı turizm uygulamaları kapsamında büyük veri kullanımını inceleyen çalışmaların ele alınması, bunların çeşitli özelliklerinin, kapsam ve sonuçlarının ortaya konması bu alandaki teorik altyapı gelişimine önemli katkılar sunacaktır.

\section{Yöntem}

Bu çalışmada, akıllı turizmde büyük veri kullanımı konulu yayınlanan makalelerin kapsamı ve içeriklerinin analiz edilerek konu hakkında teorik bilgiler elde edilmesi amaçlanmaktadır. Bu amaç doğrultusunda verilerin elde 
edilmesine sistematik derleme yöntemi kullanılmıştır. Sistematik derleme, belirli bir konuda gerçekleştirilen çalışmalardan yararlanılarak çıkarımlarda bulunmayı ve o konu hakkında kavramsal bilgi edinmeyi sağlayan araştırma yöntemidir. Literatür derleme yönteminin sistematik bir şekilde, belirli kriterlere göre gerçekleştirildiği türüdür (Hanley ve Cutts, 2013). Genellikle tıp alanında yoğun bir şekilde kullanıldığ1 görülen bu yöntem, eğitim, işletme ve yönetim (Keleher, Parker, Abdulwadud ve Francis, 2009; Tan, Muskat ve Zehrer, 2016) gibi alanlarda ve turizmde (Shafiee, Ghatari, Hasanzadeh ve Jahanyan, 2019; Ye, Ye ve Law, 2020) son yıllarda sıkça kullanılmaya başlanan bir araştırma yöntemi olarak dikkat çekmektedir.

Sistematik derleme yöntemi kullanılarak belirli bir konu hakkında gerçekleştirilen çalışmaların çeşitli kriterlere göre aranması, karşılaştırmalı olarak analiz edilmesi ve kavramsal bir çerçeve ortaya konması amaçlanmaktadır. Herkes tarafından uygulanan belirli bir sistematik derleme prosedürü olmamakla birlikte çalışma amacına en uygun içerikteki yayınlara ulaşmak bu yöntemin odak noktasını oluşturmaktadır (Shafiee vd., 2019). Bu çalışmada uygulanacak sistematik derleme için belirlenen arama kriterleri tablo 1'de gösterilmektedir.

\section{Tablo 1. Sistematik Derleme Arama Kriterleri}

\begin{tabular}{ll}
\hline Arama Kriteri & Uygulama \\
\hline Kriter 1: Veri Tabanları & $\begin{array}{l}\text { Web of Sciences, Taylor Francis, Emerald, Ebscohost, Proquest, Science Di- } \\
\text { rect, Scopus, Google Scholar }\end{array}$ \\
\hline Kriter 2: Anahtar Kelimeler & "Smart tourism and big data","smart destination and big data" \\
\hline Kriter 3: Yayın türü & Derleme ve Araştırma Makaleleri \\
\hline Kriter 4: Yayın dili & İngilizce \\
\hline
\end{tabular}

Kaynak: Tan, Muskat ve Zehrer (2016)'den uyarlanmıştır.

Bu çalışma kapsamında ilk olarak, araştırma amacına en uygun içerikteki makalelere ulaşmak için arama yapılacak uluslararası veritabanları belirlenmiştir. Bu veritabanlarında arama için kullanılacak anahtar kelimeler ve çalışma türü seçilmiştir. İngilizce dilinde yayınlanmış makalelere ilişkin aramada yayın yılına ilişkin bir sınırlama bulunmamaktadır. Tablo 1'de belirtilen veritabanlarında makale arama işlemi 20 Mayıs 2020 tarihinde yapılmıştir.

Sistematik derleme yöntemi kullanılarak yürütülen bu çalışmanın amacı doğrultusunda oluşturulan araştırma soruları (AS) şu şekildedir: 
- AS1: Akıllı turizmde büyük veri kullanımı konusunda yayınlanmış makalelerin yıllara göre dağılımı nedir?

- AS2: Akıllı turizmde büyük veri kullanımı konulu makalelerin ana temaları nelerdir?

- AS3: Akıllı turizmde büyük verinin kullanım amaçları ve sağladığı faydalar nelerdir?

Şekil 1'de, bu çalışmada sistematik derleme için yapılan makale tarama işleminin iş akış çizelgesi görülmektedir. İlk olarak, belirlenen anahtar kelimeler kullanılarak veritabanları taranmış ve toplam 1559 makaleye ulaşılmıştır. Bunların içinde tarama sonuçlarında tekrar eden makaleler elendikten sonra kalan makalelerin başlık ve özetleri incelenmiştir. Bu işlemler sonucunda içeriği çalışma amacına uygun olmayan 1457 makale daha elenmiştir. Geriye kalan 102 makalenin ise içeriklerinin tamamı incelenmiş ve 93 makale daha çalışma amacına uygun bulunmayarak elenmiştir. Dolayısıyla 9 makale bu çalışma kapsamında analize dahil edilmiştir. Konunun oldukça güncel olması nedeniyle ilgili literatürde yapılan tarama sonucu ulaşılan makalelerin sınırlı sayıda olduğu görülmektedir.

Makale tarama işlemleri kapsamında, başlık, özet ve içeriklerin incelenmesi ve makalelerin konuya uygunluğunun belirlenmesinde nesnelliği sağlamak için kodlayıcılar arası uzlaşma analizi ile güvenirlik test edilmiştir. Farklı bir zamanda, uzman başka bir araştırmacı tarafından makaleler incelenmiştir. Kodlayıcılar arası uzlaşma oranı \%97,4 (yüksek güvenirlik) olarak tespit edilmiştir. 


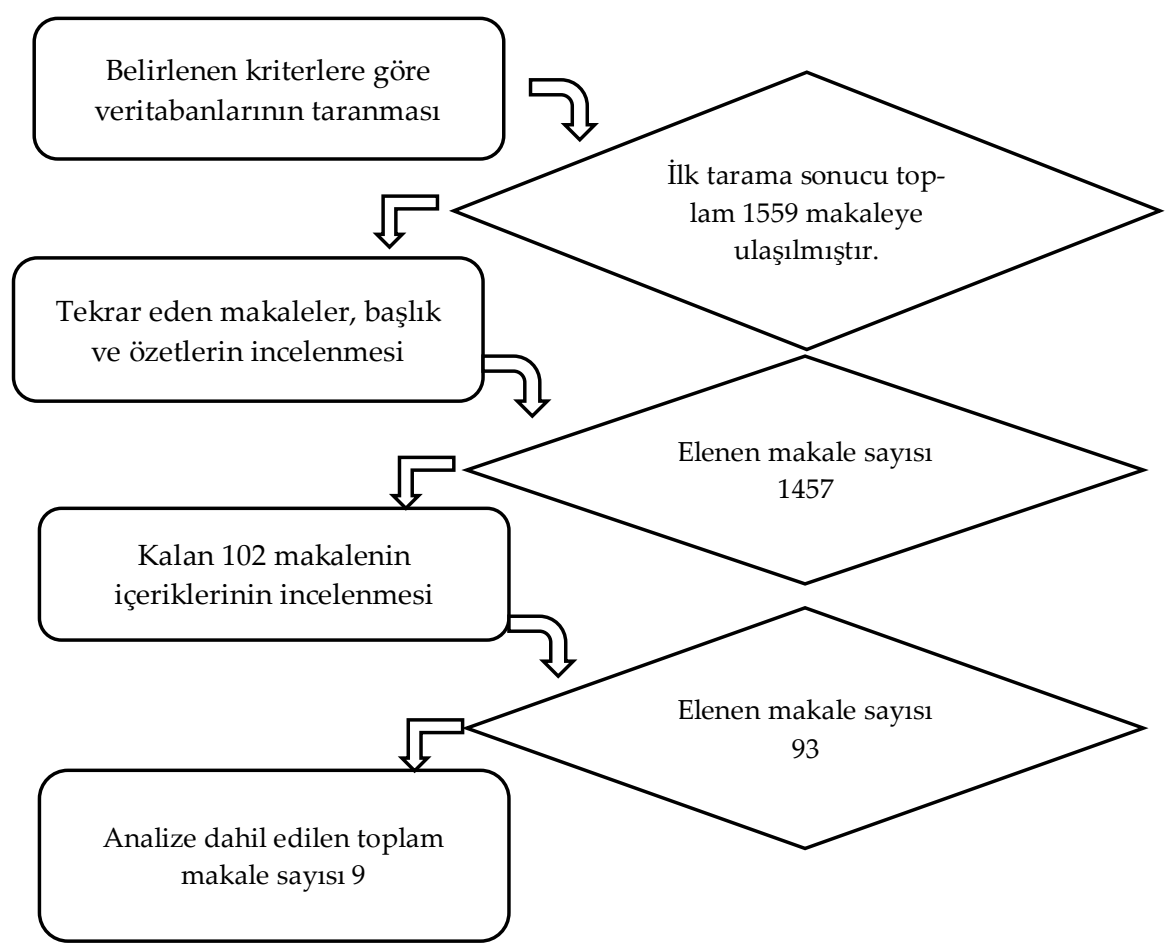

Şekil 1. Makale Arama Akış Çizelgesi

\section{Bulgular}

\section{Makalelerin Yayınlandı̆̆ı Dergiler ve Yıllara Göre Dă̆ılımlan}

Akıllı turizmde büyük veri kullanımı konulu makalelerin yayınlandığı dergiler ve yıllara göre dağılımları tablo 2'de gösterilmektedir.

\section{Tablo 2. Makalelerin Yayınlandığı Dergiler ve Yillar}

\begin{tabular}{|c|c|c|c|c|}
\hline \multicolumn{2}{|c|}{ Dergi/Yıl Dağılımı } & \multicolumn{3}{|c|}{ Yillar } \\
\hline & & 2017 & 2018 & 2019 \\
\hline \multirow{6}{*}{ 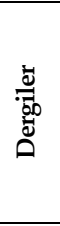 } & International Journal of Contemporary Hospitality Management & & 1 & \\
\hline & Sustainability & 2 & & \\
\hline & Information Processing and Management & & 1 & \\
\hline & Procedia Computer Science & & 1 & \\
\hline & Applied Science & & 1 & \\
\hline & Current Issues in Tourism & & & 3 \\
\hline
\end{tabular}

Tablo 2'deki verilere göre, akıllı turizmde büyük veri kullanımı konulu 6 farklı dergide toplam 9 makale yayınlandı̆̆ı görülmektedir. Yayınlanan makalelerin yıllara göre dağılımları ise 2017, 2018 ve 2019 yıllarıdır. 


\section{Ana Temalarına Göre Makalelerin Dağılımı}

Grafik 1'de, makalelerin ana temaları bakımından dağılımı yer almaktadır.

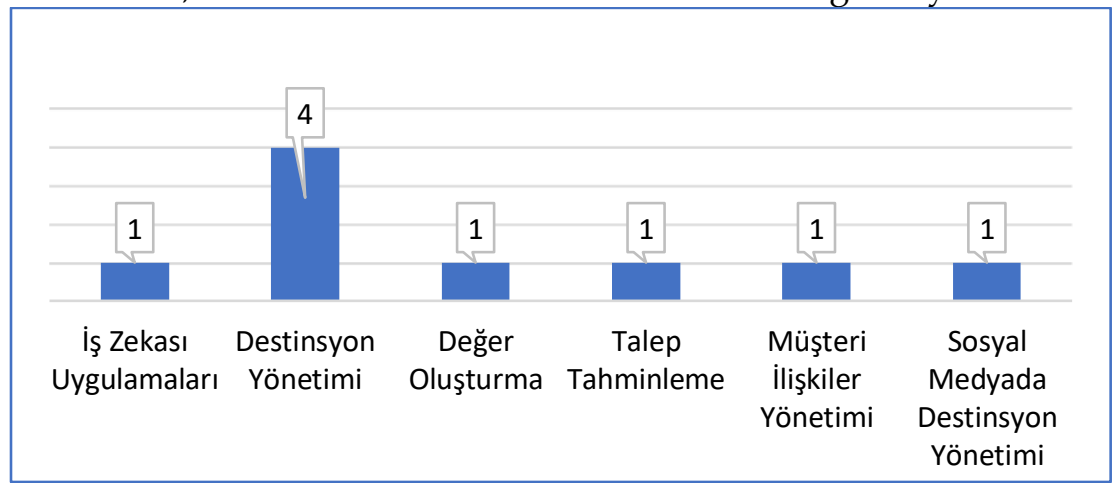

\section{Grafik 1. Ana Temalara Göre Makalelerin Dağılımı}

Grafik 1 incelendiğinde, akıllı turizmde büyük veri kullanımı konulu makalelerin ana temalarının genellikle destinasyon yönetimi olduğu görülmektedir $(n=4)$. Bununla birlikte, sosyal medyada destinasyon yönetimi, değer oluşturma, müşteri ilişkileri yönetimi, talep tahminleme ve turizm iş zekası uygulamaları gibi temaların bu makalelerde çalışıldığı görülebilmektedir.

\section{Makalelerin Sonuçlarna İlişkin Bulgular}

Bu çalışmada kapsamında incelenen makalelerin sonuç kısımları, akıllı turizmde büyük veri kullanımı bağlamında analiz edilmektedir. Sonuçlar genel olarak değerlendirildiğinde, akıllı turizm uygulamalarında işletme ve destinasyon bazında çeşitli amaçlarla büyük verinin kullanıldı̆̆ görülmektedir. 9 makalenin sonuç kısımlarının özeti şu şekildedir:

$>$ Makale 1 (Mariani vd., 2018): Büyük veri analizi turizmde son yıllarda önem kazanan güncel konular arasında dikkat çekmektedir. Büyük miktarlardaki verinin analitik olarak incelenmesi ve işlenerek anlamlı hale getirilmesi turizm işletmeleri ve destinasyonlar için oldukça önemlidir. Ziyaretçi davranışlarını anlamak ve onları takip etmek için akıllı teknolojiler turizm endüstrisinde etkin bir şekilde kullanılmakta, büyük veri bu teknolojiler yardımıyla toplanmakta ve işlenebilmektedir. Bununla bir- 
likte, turizmde akıllı teknolojiler kullanılarak çeşitli iş zekası uygulamaları da geliştirilebilmekte ve büyük veri kullanılmaktadır. İlgili literatürde bu konudaki çalışmaların kısıtlı sayıda olması vurgulanması gereken diğer önemli hususlardan biri olarak değerlendirilebilir.

$>$ Makale 2 (Khan, Woo, Nam ve Chathoth, 2017): Ak1ll turizmin bir parçası olan akıllı destinasyonlarda gerekli olan bilgiler büyük verilerden elde edilebilir. Bu büyük verilerin işlenmesinde akıllı teknolojilerden yararlanilabilir.

D Makale 3 (Vecchio, Mele, Ndou ve Secundo, 2018): Sosyal medya, mobil akıllı teknolojilerin kullanımının yaygınlaşması büyük verileri meydana getirmektedir. Akıllı destinasyonların günümüzde, sosyal medyadaki büyük verilerden yararlanarak ziyaretçi deneyimlerini artırması, kişiselleştirilmiş deneyimler sunması, değer oluşturması ve rekabet avantajı elde etmesi mümkündür.

$>$ Makale 4 (Boulaalam, Aghoutane, Ouadghiri, Moumen ve Malinine, 2018): Turistlerle ilgili büyük verinin analizinde, onların davranışlarının, tercihlerinin ve satın alma kararlarının anlaşılmasında destinasyonlarda kullanılabilecek akıllı sistemler mevcuttur. Turizm yöneticileri turistler hakkında bilgiyi yöneterek akıllı destinasyonlar oluşturabilirler.

$>$ Makale 5 (Chen, Chen ve Yang, 2018): Aynı anda binlerce sunucu ile çal1şabilen yazılımlarla turizm endüstrisindeki büyük hacimli veriyi işlemek ve yönetmek gerekmektedir. Ayrıca, destinasyonlarda akıllı turizmin geliştirilmesi için büyük verinin elde edilmesinde bu yazılımlar önemli avantajlar sağlamaktadır. Ziyaretçi istek ve beklentilerinin tespit edilmesi büyük verinin analiz edilmesi ile mümkün olabilmektedir. Böylece, bu istek ve beklentilere uygun akıllı turizm uygulamaları geliştirmek ve ziyaretçi memnuniyetini artırmak turizm işletmesi ve destinasyonlara değer katacaktır.

$>$ Makale 6 (Shao, Chang ve Morrison, 2017): Turizm endüstrisinde artan sosyal medya kullanımı, düşük maliyetlerle büyük veriye ulaşma imkanı sağlamaktadır. Seyahat blogları, destinasyonlar ve kişilerin seyahat davranışları hakkında önemli birer veri kaynağı durumundadır. Büyük veri analizlerine dayalı akıllı turizm stratejileri kullanılarak destinasyonların yönetimi ve ziyaretçi tercihlerinin, davranışlarının izlenmesi mümkündür. 
$>$ Makale 7 (Ardito, Cerchione, Vecchio ve Raguseo, 2019): Akıll turizmde büyük veri talep tahminleme, karar alma, bilgi akışını yönetme, müşteri ilişkileri yönetimi ve kişiye özel hizmet sunumlarında kullanılabilmektedir. Böylece büyük verilerin akıllı uygulamalarla birlikte etkin bir şekilde kullanılması ve etkileşimin artırılması mümkün olacaktır. Bunun sonucunda, turizmde verimlilik, memnuniyetle birlikte destinasyonların ve turizm işletmelerinin rekabet gücü artmaktadır.

> Makale 8 (Centobelli ve Ndou, 2019): Turizm endüstrisindeki işletmeler ve destinasyonlarda akıllı turizm uygulamalarının geliştirilmesinde ve böylece turist deneyimlerinin artırılmasında büyük veri önemli bir araç olarak kullanılabilir. Turist deneyimlerinin şekillendirilmesinde teknoloji günümüzde önemli bir rol oynamaktadır. Büyük veriye dayalı akıllı turizm uygulamalarının geliştirilmesi, daha zengin ve kişiye özel deneyimler oluşturulmasına, daha fazla katma değerli hizmet sunulmasına ve müşteri memnuniyetinin artmasına neden olmaktadır. Sosyal ağlar turistler hakkında büyük verilerin elde edilmesinde en önemli kaynaklardir.

$>$ Makale 9 (Villamediana-Pedrosa, Vila-Lopez ve Küster-Boluda, 2019): Akıllı teknolojiler ve sosyal medya kullanılarak elde edilen büyük veriler işlenip analiz edilerek müşteri ilişkileri oluşturmak mümkündür. Sosyal medya yönetiminde işletme ve destinasyonlar tarafından büyük veriler kullanılabilmekte, kişiye özel mesajlar verilebilmektedir. Ziyaretçilerin Facebook, Twitter, YouTube gibi çeşitli sosyal medya araçlarını bilgi kaynağı olarak kullanmaları ve işletme ile bu mecra üzerinden iletişime geçmeleri, aynı zamanda önemli bir veri kaynağı elde edilmesine de neden olmaktadır.

\section{Tartışma ve Sonuç}

Son yıllarda kişiler arasında internet ve sosyal medya kullanımının yaygınlaşması, bu mecraları kişiler hakkında çeşitli veriler elde etme açısından önemli bir kaynak durumuna getirmektedir. Çevrimiçi ortamda kişilerin kurduğu iletişim, yaptığ 1 iş ve işlemlerin hepsi birer veri olarak kaydedilmekte ve depolanmaktadır. Büyük boyutlara ulaşan bu verilerin, günümüzde işletmeler tarafından analiz edilerek kullanıldığı görülmektedir. İşletmelerin faaliyetlerini gerçekleştirmede kullandıkları akıllı teknolojiler ve uygulamalar, 
aynı zamanda büyük verilerin elde edilmesinde önemli bir araç olabilmektedir (Mariani vd. 2018). Bununla birlikte, turizm endüstrisinde ak1llı teknolojiler kullanılarak hizmet üretilmesinde büyük veriden faydalanılması güncel yeni çalışma konuları arasında dikkat çekmektedir.

Büyük veriyi, son yıllarda sosyal bilimler alanında ilgi çeken araştırma konularından biri olarak değerlendirmek mümkündür. Bu alanlardan biri de turizmdir. Gerek akademik araştırmalar gerekse sektörel uygulamalarda büyük veri kullanımının önemli bir konu durumuna geldiği görülmektedir. İlgili literatür incelendiğinde, turizm ve büyük veri hakkında yapılan çalışmalarda son dönemde bir artış olduğu gözlenmektedir. Bununla birlikte, büyük verinin turizm işletmelerinde ve destinasyonlarda akıllı uygulamalarla birlikte kullanılması akademik alanda henüz yeni bir konu olarak değerlendirilebilir. Bu çalışmadan elde edilen sonuçlar, akıllı turizmde büyük veri kullanımına ilişkin 2017, 2018 ve 2019 yıllarında yayınlanan sınırlı sayıda uluslararası makale çalışmasının olduğunu göstermektedir. Büyük veri ve akıllı turizm teknolojilerinin ayrı ayrı ele alındığı çalışmalar daha fazla olmakla birlikte (Kontogianni ve Alepis, 2020; Liberato, Alen-Gonzalez ve Liberato, 2018; Shang ve You, 2019) bu iki kavramı ilişkilendiren çalışmaların da gerçekleştirilmesinin ilgili literatürün gelişimine önemli katkılar sunacağı düşünülmektedir.

Akıllı turizmde büyük veri kullanımına yönelik makalelerin çoğunlukla destinasyon yönetimi ana teması altında olduğu görülmektedir. Bununla birlikte, veri analizi ile ilgili iş zekası uygulamaları, müşteri ilişkileri, sosyal medyada destinasyon yönetimi, değer oluşturma ve talep tahminleme bu makalelerdeki diğer ana temalardır. Destinasyonlarda akıllı turizm uygulamaları ve büyük verinin kullanımı bu ana temalar ile birleştirilerek çalışmalar gerçekleştirilmiştir. Benzer şekilde, turizm işletmelerinde akıllı teknolojiler kullanılarak büyük veri elde edilmesi, analizi ve bunların kullanılmasının çeşitli açlardan bu makalelerde ele alındığı görülmektedir. Analiz edilen makalelerde dikkat çeken en önemli veri kaynağı olarak ise sosyal medyanın olduğu görülmektedir. Sosyal medya, günümüzde turizmde sıklıkla kullanılan önemli bir bilgi ve iletişim kaynağı olmasının yanında (Berhanu ve Raj, 2020), aynı zamanda büyük bir veri kaynağı olarak da nitelendirilebilir. Dolayısıyla, akıllı turizm uygulamalarında sosyal medyadan yararlanılarak elde edilen veriler önemli bir araç olarak değerlendirilebilir. Turizm endüstrisindeki profesyoneller tarafından, sosyal medyanın büyük veri sağlama özelliği etkin bir 
şekilde kullanılarak akıllı uygulamalar geliştirilebilir. Böylece kişiye özel hizmet sunumlarıyla müşteri memnuniyeti artırılabilir ve rekabet avantajı elde edilebilir.

Destinasyonlarda ve turizm işletmelerinde akıllı turizm kapsamında büyük veri kullanımının sağladığı katkılar ve yapılan çıkarımların analizi amacıyla makalelerin sonuç bölümleri incelenmiştir. Ziyaretçiler hakkında bilgi elde etmede büyük veri önemli bir araç olarak görülmekteyken, sosyal medya büyük verinin elde edildiği en büyük kaynak olarak gösterilmektedir. Analiz edilen makalelerden elde edilen sonuçlara göre, turist davranışlarının, tercihlerinin anlaşılması, turizm talebinin tahminlenmesi, akıllı sistemler geliştirilerek verimliliğin ve memnuniyetin arttırılması sağlanabilir. Turizm işletmelerinde müşteri memnuniyetinin artması, sadık müşteriler oluşturulmasını sağlayabilmekte, böylece artan satışlar daha fazla karlılığa neden olabilmektedir. Yoğun rekabet ortamında avantaj elde ederek varlıklarını devam ettirme çabasındaki turizm işletmeleri için, akıllı turizm uygulamalarında büyük veri kullanımı kritik öneme sahip bir yönetim stratejisi olarak nitelendirilebilir. Başka bir ifadeyle, akıllı turizmin geliştirilmesinde büyük verinin önemli bir araç olarak gösterilmesi mümkündür. Gelecekteki çalı̧̧malarda konunun uygulamalı bir araştırma şeklinde ele alınarak birincil veriler elde edilmesi mümkündür. Bu kapsamda turizm işletmesi yöneticileri ile derinlemesine görüşme gerçekleştirilebilir veya anket tekniği kullanılabilir. Turizm işletmesi yöneticilerinin akıllı turizmde büyük veri kullanımına yönelik tutumları ele alınabilir. Destinasyon ve turizm işletmelerinde büyük veriden faydalanılarak geliştirilen akıllı turizm uygulamalarına yönelik turistlerin tutumlarının incelenmesi de farklı bir çalışma konusu olarak düşünebilir. 


\title{
EXTENDED ABSTRACT
}

\section{Use of Big Data in Smart Tourism: A Systematic Review}

\author{
Fatih Ercan \\ Zonguldak Bülent Ecevit University
}

It is seen that the digital transformation in the world in recent years has reached great dimensions with the development of new technologies today. With the widespread use of the internet among people, new technologies have started to emerge and develop. Social media, smart mobile applications, artificial intelligence, internet of things (IoT) and big data are among these new technologies. The use of smart mobile phones and increased internet access make social media an important communication and sharing platform. Information, content and posts in user profiles on social media cause some data about people to be digitized. Similarly, various websites can be an important data source where user information is stored. Along with the increasing number of users, the data on the digital media are increasing and reaching large amounts.

Big data refers to the "evolution and use of technologies that provide the right user at the right time with the right information from a mass of data that has been growing exponentially for a long time in our society" (Riahi and Riahi, 2018: 524). Big data about users obtained through websites and social media is important for tourism businesses as well as businesses operating in different industries today. Yallop and Seraphin (2020) state that big data is one of the most important tools used in personalized service delivery in the tourism industry. Liu et al. (2019) state that there is also big data on the internet about businesses and destinations in the tourism industry. The authors emphasize that it is difficult for people to access travel options that are suitable for their preferences from this big data online. Shafiee and Ghatari (2016) state that with the increasing digitalization, the amount of data in the world has increased and this big data offers important opportunities in creating 
smart travel experiences in the tourism industry. Therefore, big data is an important tool for both service providers and consumers in the tourism industry.

In the tourism industry, there has been an increase in research and practices for the analysis of large amounts of data in recent years (Mariani et al., 2018). However, today, it is possible to develop smart technologies and use them in various fields by using the information obtained from big data analysis. It is seen that the smart technology machines developed in this way are used to create innovation in decision making and business processes as well as physical production (Shang and You, 2019). With smart technologies created using big data obtained from various online platforms, it is possible to forecast demand ( $\mathrm{Li}, \mathrm{Hu}$ and $\mathrm{Li}, 2020)$, customer information management (Centobelli and Ndou, 2019), to determine visitor behaviors and preferences (Iorio et al., 2019). The smart technologies developed using big data are an important information support tool for businesses in the tourism industry. In addition, the use of big data in smart tourism stands out among the topics studied in the relevant academic literature in recent years.

In this study, it is aimed to obtain theoretical information by analyzing the scope and contents of articles published about the use of big data in smart tourism. For this purpose, systematic review method was used to obtain data. This method, which is seen to be widely used in the field of medicine, is also used in fields such as education, management (Keleher et al., 2009; Tan, Muskat and Zehrer, 2016) and tourism (Shafiee et al., 2019; Ye, Ye and Law, 2020) in recent years. By using systematic review method, it is aimed to search the studies carried out on a specific subject according to various criteria, analyze them comparatively and create a conceptual framework. Firstly, international databases to be searched were determined in order to reach the articles with the most suitable content for the research purpose. In these databases, the keywords to be used for search and the type of study are selected. There is no restriction on the year of publication in the search for articles published in English. Searching for articles in databases shown in Table 1 was carried out on 20 May 2020.

Databases were scanned using the specified keywords and 1559 articles were reached as a result of this process. After eliminating the repeating articles, the titles and abstracts of the remaining articles were examined. As a result of these processes, 1457 articles whose content was not suitable for the 
purpose of study were eliminated. As a result of the detailed examination of the contents of the remaining 102 articles, 93 more articles were eliminated. As a result of the elimination process, 9 articles that were found to be relevant were included in the analysis within the scope of this study. According to the findings, it is seen that a total of 9 articles were published in 6 different journals on the use of big data in smart tourism. Distribution of published articles by years is 2017, 2018 and 2019. Also, the main themes of articles on the use of big data in smart tourism are generally destination management $(n=4)$. However, it can be seen that themes such as destination management on social media, value creation, customer relationship management, demand forecasting and tourism business intelligence applications are studied in these articles.

In order to analyze the contribution of big data usage within the scope of smart tourism applications in destinations and tourism businesses, the conclusion sections of the articles were examined. While big data is seen as an important tool in obtaining information about visitors, social media is shown as the biggest source of big data in these articles. According to the results obtained from the analyzed articles, it can be possible to understand tourist behaviors, preferences, to predict tourism demand, to increase efficiency and satisfaction by using big data and smart technologies. In addition, it is possible to show big data as an important tool in the development of smart tourism applications. In the future studies, further investigation of the subject with different research methods will provide important contributions to the development of the literature in this field.

\section{Kaynakça / References}

Aktan, E. (2018). Büyük veri: Uygulama alanları, analitiği güvenlik boyutu. Bilgi Yönetimi Dergisi, 1(1), 1-22.

Altunışık, R. (2015). Büyük veri: Fırsatlar kaynağı mı yoksa yeni sorunlar yumağı mı?, Yildı Social Science Review, 1(1), 45-76.

Ardito, L., Cerchione, R., Vecchio, P. D. ve Raguseo, E. (2019). Big data in smart tourism: challenges, issues and opportunities. Current Issues in Tourism, 22(15), 18051809.

Berhanu, K. ve Raj, S. (2020). The trustworthiness of travel and tourism information sources of social media: Perspectives of international tourists visiting Ethiopia. Heliyon, 6, 1-10. 
Boulaalam, O., Aghoutane, B., Ouadghiri, D. E., Moumen, A., vve Malinine, M. L. C. (2018). Proposal of a big data system based on the recommendation and profiling techniques for an intelligent management of Moroccan tourism. Procedia Computer Science, 134, 346-351.

Centobelli, P. ve Ndou, V. (2019). Managing customer knowledge through the use of big data analytics in tourism research. Current Issues in Tourism, 22(15), 18621882.

Chen, W.-C., Chen, W.-H. ve Yang, S.-Y. (2018). A big data and time series analysis technology-based multi-agent system for smart tourism. Applied Sciences, 8, 1-21.

Doğan, K. ve Arslantekin, S. (2016). Büyük Veri: Önemi, Yapısı ve Günümüzdeki Durum. DTCF Dergisi, 56(1), 15-36.

Femenia-Serra, F., Neuhofer, B. ve Ivars-Baidal, J. (2019). Towards a conceptualisation of smart tourists and their role within the smart destination scenario. The Service Industries Journal, 39(2), 109-133.

Hanley, T. ve Cutts, L. (2013). What is a systematic review?. Counselling Psychological Society, 28(4), 3-6.

Iorio, C., Pandolfo, G., D'Ambrosio, A. ve Siciliano, R. (2019). Mining big data in tourism. Quality \& Quantity, 54, 1655-1669. https://doi.org/10.1007/s11135-01900927-0.

Keleher, H., Parker, R., Abdulwadud, O. ve Francis, K. (2009). Systematic review of the effectiveness of primary care nursing. International Journal of Nursing Practice, $15,16-24$.

Khan, M. S., Woo, M., Nam, K. ve Chathoth, P. K. (2017). Smart city and smart tourism: A case of Dubai. Sustainability, 9, 1-24.

Kontogianni, A. ve Alepis, E. (2020). Smart tourism: State of the art and literature review for the last six years. Array, 6, 1-12.

Koyuncu, E. (2016). Kalkınma için büyük veri. 20 Mayıs 2020 tarihinde https://www.tepav.org.tr/upload/files/1452171925-1.Kalkinma_Icin_Buyuk_Veri.pdf adresinden erişilmiştir.

Li, H., Hu, M. ve Li, G. (2020). Forecasting tourism demand with multisource big data. Annals of Tourism Research, 83, 102912.

$\mathrm{Li}$, X. ve Law, R. (2020). Network analysis of big data research in tourism. Tourism Management Perspectives, 33, 100608.

Li, Y., Hu, C., Huang, C. ve Duan, L. (2017). The concept of smart tourism in the context of tourism information services. Tourism Management, 58, 293-300. 
Liu, X., Zou, J., Liu, L. ve Cheng, P. (2019). Research on scenic spots recommendation algorithm based on tourism big data. 4th International Conference on Mechanical, Control and Computer Engineering (ICMCCE), 25-27 October, Hohhot, Chia, 926-929.

Liberato, P. M. da C., Alen-Gonzalez, E. ve Liberato, D. F. V.de A. (2018). Digital technology in a smart tourist destination: The case of Porto. Journal of Urban Technology, 25(1), 75-97.

Mariani, M., Baggio, R., Fuchs, M. ve Höepken, W. (2018). Business intelligence and big data in hospitality and tourism: A systematic literature review. International Journal of Contemporary Hospitality Management, 30(12), 3514-3554.

Riahi, Y. ve Riahi, S. (2018). Big data and big data analytics: Concepts, types and technologies. International Journal of Research and Engineering, 5(9), 524-528.

Shafiee, S. ve Ghatari, A. R. (2016). Big data in tourism industry. 10 th International Conference on e-Commerce with Focus on e-Tourism, 15-16 April, Isfahan, Iran, 1-7.

Shafiee, S., Ghatari, A. R., Hasanzadeh, A. ve Jahanyan, S. (2019). Developing a model for sustainable smart tourism destinations: A systematic review. Tourism Management Perspectives, 31, 287-300.

Shang, C. ve You, F. (2019). Data analytics and machine learning for smart process manufacturing: Recent advances and perspectives in the big data era. Engineering, 5, 1010-1016.

Shao, J., Chang, X. ve Morrison, A. M. (2017). How can big data support smart scenic area management? An analysis of travel blogs on Huashan. Sustainability, 9, 117.

Tan, A. H. T., Muskat, B. ve Zehrer, A. (2016). A systematic review of quality of student experience in higher education. International Journal of Quality and Service Sciences, 8(2), 209-228.

Vecchio, P. D., Mele, G., Ndou, V. ve Secundo, G. (2018). Creating value from social big data: Implications for smart tourism destinations. Information Processing and Management, 54, 847-860.

Villamediana-Pedrosa, J. D., Vila-Lopez, N. ve Küster-Boluda, I. (2019). Secrets to design an effective message on facebook: An application to a touristic destination based on big data analysis. Current Issues in Tourism, 22(15), 1841-1861.

Volo, S. (2020). Tourism statistics, indicators and big data: A perspective article. Tourism Review, 75(1), 304-309. 
Xu, C., Huang, X., Zhu, J. ve Zhang, K. (2018). Research on the construction of Sanya smart tourism city based on internet and big data. International Conference on Intelligent Transportation, Big Data \& Smart City. 25-26 January, Xiamen, China, 125-128.

Yallop, A. ve Seraphin, H. (2020). Big data and analytics in tourism and hospitality: Opportunities and risks. Journal of Tourism Futures, Ahead of Print, DOI: https://doi.org/10.1108//TF-10-2019-0108.

Ye, B. H., Ye, H. ve Law, R. (2020). Systematic review of smart tourism research. Sustainability, 12, 1-15.

Yin, H. ve Zhu, Y. (2017). The influence of big data and informatization on tourism industry. International Conference on Behavioral, Economic, Socio-Cultural Computing (BESC), 16-18 October, Krakow, Poland. 1-5.

\section{Kaynakça Bilgisi / Citation Information}

Ercan, F. (2020). Akıllı turizmde büyük veri kullanımı: Sistematik bir derleme. OPUS-Uluslararası Toplum Araştırmaları Dergisi, 16(32), 52305249. DOI: $10.26466 /$ opus.780017 